\title{
Saúde em São Paulo: aspectos da implantação do SU S no período de 2001-2002
}

\author{
EDUARDO JORGE MARTINSA LVES SOBRINHO \\ e PAULO FERNANDO CAPUCCI
}

\section{Introdução ( Por Eduardo J orge M artins A lves Sobrinho )}

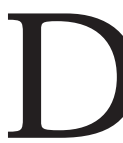

U RANTE os últimos vinte anos fui um observador privilegiado das políticas públicas no Brasil, pois era um dos responsáveis do meu partido, 0 PT, pelo tema Seguridade Social (Assistência Social, Previdência e Saúde). C onstituinte, Comissão de Seguridade Social, Comissões E speciais de I nquérito e de reformas, Comissão de O rçamento da Câmara Federal, Comissões de emendas constitucionais, interlocução com ministérios, Conselho $\mathrm{N}$ acional de Saúde, entidades de profissionais de saúde, previdência e assistência social, secretarias municipais e estaduais de saúde etc. Todos esses espaços de diálogo me deram uma convicção: a proposta constitucional aprovada em 1988 e em andamento nos últimos catorze anos chamada Sistema Ú nico de Saúde (SU S) é a única proposta geneticamente socialista em andamento no Brasil. Socialista no seu sentido amplo, universalista, democrático e igualitário e não no seu modelo mais conhecido, autoritário e estatista.

O ra, uma proposta socialista em um país capitalista e extremamente desigual como o Brasil, onde os próprios trabalhadores estão separados por abismos vertiginosos nos seus estilos de vida, não pode ter vida fácil.

Em São Paulo, capital econômica do país e exemplo extremo das nossas disparidades sociais, foi particularmente difícil a chegada do SU S. O s primeiros passos dados pela Prefeita Luiza Erundina (1989-1992) foram bruscamente interrompidos por duas gestões extremamente reacionárias que tentaram uma experiência de privatização selvagem que destruiu a rede municipal de saúde (uma poderosa rede com mais de quarenta mil trabalhadores de saúde) e que acabou se tornando um caso de polícia pelos seus desmandos e irregularidades administrativas e financeiras.

A posse da Prefeita M arta Suplicy (2001) possibilitou, apesar de todosesses anos de atraso, que o SU S, em sua articulação federal, estadual, municipal e popular, começasse de fato em São Paulo.

É sobre esse período de 2001, 2002 e início de 2003 que vamos apresentar al gumas considerações ainda iniciais, com base em documentos gerados no perío- 
do, que esperamos ser úteis a outros militantes que constroem o SU S pelo Brasil afora mesmo sabendo que alguns têm muito mais experiência do que nós de São Paulo e sabendo de como São Paulo é diferente de Blumenau, de Camaragibe e de $\mathrm{M}$ arechal Taumaturgo, por exemplo.

\section{Saúde em São Paulo, dificuldades e esperança}

É preciso ressaltar, em primeiro lugar, que o SU S é uma política pública constitucional e nacional. U m esforço concertado dos Governos Federal, Estaduais e M unicipais. Portanto, não é promessa ou marca da administração $A$ ou $B$, de partido político C ou D. É importante para a perenidade da política pública, na alternância democrática de governos, que não se fixe prioritariamente no critério político partidário para nomear gestores, tais como nossos diretores de $D$ istritos de Saú de e hospitais.

Em segundo lugar, pode-se dizer que a atenção primária comanda o sistema. A lógica do sistema de saúde brasileiro coloca hoje em seu comando o super especialista e o hospital ultra especializado. 0 novo farol deve ser a promoção, a prevenção, a educação, a atenção primária e o estímulo ao autocuidado orientado cientificamente - como elemento racionalizador da atenção à saúde, e mesmo como elemento de autonomia do cidadão frente aos profissionais de saúde.

Finalmente, deve ser lembrado que não existe nem perseguição nem privilégio. U m princípio especialmente válido para o caso de São Paulo. $\mathrm{N}$ em perse gui ção, nem privilégi o. U ma só lei para todos é a única forma de promover uma pacificação num corpo de servidores com mais de quarenta mil pessoas, profundamente dividido entre os que foram para a experiência trágica da privatização por meio de falsas cooperativas e os que foram jogados no "exílio".

Seguindo estes três princípios caminhamos em cinco frentes de reforma simultâneas:

\section{Reconstrução da Secretaria M unicipal de Saúde}

A Secretaria de M unicipal da Saúde (SM S) estava fraturada em vários pedaços: treze mil funcionários no que sobrou da Secretaria; dezessete mil trabal hadores nas falsas cooperativas, sendo cinco mil funcionários e doze mil não concursados; dez mil servidores públicos "exilados" em outras secretarias. U ma mega movimentação de pessoal feita com o máximo de prudência e tolerância foi concluída em julho de 2001. Parte dos treze mil funcionários de SM S foi remanejada para cobrir claros em áreas carentes; os cinco mil funcionários das cooperativas retornaram à SM S; os doze mil contratados irregularmente nas cooperativas foram dispensados; dez mil trabalhadores foram contratados de emergência e cinco mil servidores "exilados" retornaram.

0 mais importante é que a estratégia de fazer uma transição respeitando a lei municipal e os prazos dos contratos das cooperativas (26/6/2001) possibilitou completar esta dificílima o peração administrativa sem que a rede entrasse em colapso, fato que muitos previam como inevitável. 
Entre 2001 e 2003 realizamos concursos públicos. O s contratados de emergência foram substituídos por funcionários concursados e atingimos, em 2003, 0 total de 44 mil trabalhadores da saúde na SM S.

A remuneração dos profissionais foi recuperada com uma gratificação emergencial. 0 salário do médico contratado por vinte horas semanais, por exemplo, passou de $R \$ 764,00$ para $R \$ 1.911,00$, com o número de médicos passando de cinco mil em dezembro de 2000 para 5.850 em julho de 2001, e daí para sete mil já no início de 2003. O s estoques de medicamentos foram repostos. A recuperação física dos serviços começou mais lentamente, pois o estrago é muito grande e o orçamento modesto.

\section{Trazer o SU S para São Paulo}

Em primeiro lugar, devemos dizer que este é um trabalho sintonizado entre governos Federal, Estadual e M unicipal. O diálogo rompido foi retomado e desde o final do ano 2001 todas as unidades básicas estaduais sediadas na capital (cerca de duzentas) estão funcionando articuladas com as unidades básicas municipais (cerca de 250) sob a gerência unificada de SM S. Em novembro de 2002, a Secretaria deu entrada no pedido de gestão plena do sistema municipal. Estão em andamento as nego ciações para o repasse à nossa gerência, de to dos os hospitais estaduais e outros tantos serviços especial izados estaduais sediados na capital, assim como o acompanhamento dos serviços de saúde privados, filantrópicos e lucrativos, conveniados com o SU S na cidade.

\section{D istritalização}

E m janeiro de 2001 criamos 41 D istritos de Saúde, com uma média de 250 mil habitantes em cada um deles. Esta iniciativa possibilita a identificação clara de um território, onde desde as atividades preventivas e de vigilância até a reabilitação ficarão sob o comando de uma autoridade sanitária local. Em 2002, esse número foi corrigido para 39 D istritos de Saúde inseridos nos limites territoriais nas recém-instituídas 31 subprefeituras do município de São Paulo

Agora estamos formando os quatrocentos dirigentes das unidades básicas com uma base sólida técnica-administrativa e de compromisso com o SU S. 0 Gerus $^{1}$ é um curso de um ano de duração, ao término do qual os profissionais recebem o título de especialista em gerência de serviços básicos de saúde.

\section{M odernização da G estão}

Informatizar. Sair do zero absoluto em termos de informatização como encontramos a Secretaria M unicipal de Saúde em 2001 para primeiro al cançar os estágios que o SU S como um to do já al cançou, tanto na rede básica como hospitalar. Resistir aos lobbies maliciosos e mirabolantes que querem impor sistemas caríssimos e desvinculados do que o SU S está construindo em conjunto.

Acreditar na importância do C artão SU S e no seu potencial. N ão se ater à mesquinharia e rejeitar uma proposta porque é "Federal" e vinda de uma instância governamental que era controlada por outro partido político que não o nos- 
So. E stamos com quatro milhões de cadastrados no cartão SU S esperando, agora em 2003, qual será o passo seguinte neste programa a ser dado em conjunto com o novo Governo Federal.

Acreditar na importância do Cartão SU S e no seu potencial. N ão se ater à mesquinharia e rejeitar uma proposta porque é "Federal" e vinda de uma instância governamental que era controlada por outro partido político que não o nosso. Estamos com quatro milhões de cadastrados no cartão SU S esperando, agora em 2003, qual será o passo seguinte neste programa a ser dado em conjunto com o novo Governo Federal.

Ter coragem de inventar novas formas ou reinventar velhas formas adaptando-as à nossa realidade: L ei das Autarquias H ospitalares, Projeto de L ei criando a Agência de Vigilância em Saúde, Projeto de Lei criando o contrato de gestão por equipes de saúde, Projeto de Lei para contratação de cargos de difícil provimento, Projeto de L ei para financiamento de serviços para dependentes de drogas, Projeto de Lei prevendo concurso para chefias de unidades com interveniência dos C onselhos de Saúde etc.

\section{Programa Saúde da Família (PSF)}

Embora sem uma clara prioridade no orçamento nacional do SU S, que continua privilegiando os procedimentos terciários, o projeto mais importante do SU S é o PSF. Em oito anos de trabalho no Brasil já temos quinze mil equipes atendendo cinqüenta milhões de pessoas.

Aqui, em São Paulo, este programa, que é essencialmente municipal na sua gerência, não foi assumido pelas gestões anteriores. I sso obrigou os Governos federal e estadual a iniciá-lo implantando em seis anos (até fins de 2000) cerca de 180 equipes. Agora, trata-se de multiplicar estas equipes por dez, atingindo em 20040 número de 1.700 equipes.

A Prefeitura firmou convênio com doze entidades de tradição na assistência social e em saúde em São Paulo², para cumprir esta tarefa. E m tempo recorde, atingimos em 2002 o número de setecentas equipes que já cuidam de mais de dois milhões de paulistanos. Em números absolutos, a capital do Estado já é a cidade do país com maior cobertura.

O PSF é a organização, pela primeira vez no Brasil, de uma verdadeira porta de entrada do sistema de saúde. Ele deve, sobretudo, reestruturar todos os outros níveis de atenção à saúde, além de ser uma reforma humanitária, pois o cidadão volta a conhecer o seu médico, a sua enfermeira e vice-versa.

Existe ainda um sexto movimento que, por ser global e atravessar todas as cinco reformas anteriores, queremos ressal tar aqui: é a humanização dos serviços de saúde. Os técnicos batizaram com um nome técnico - acolhimento. Para nós isto não passa da aplicação do princípio revolucionário de dois mil anos atrás: amar ao próximo como a si mesmo. Tratar o outro como gostaria de ser tratado a si mesmo. 
M apa 1 - U nidades de Saúde da rede M unicipal, Estadual, Federal e privada conveniada no M unicípio de São Paulo, 2003.

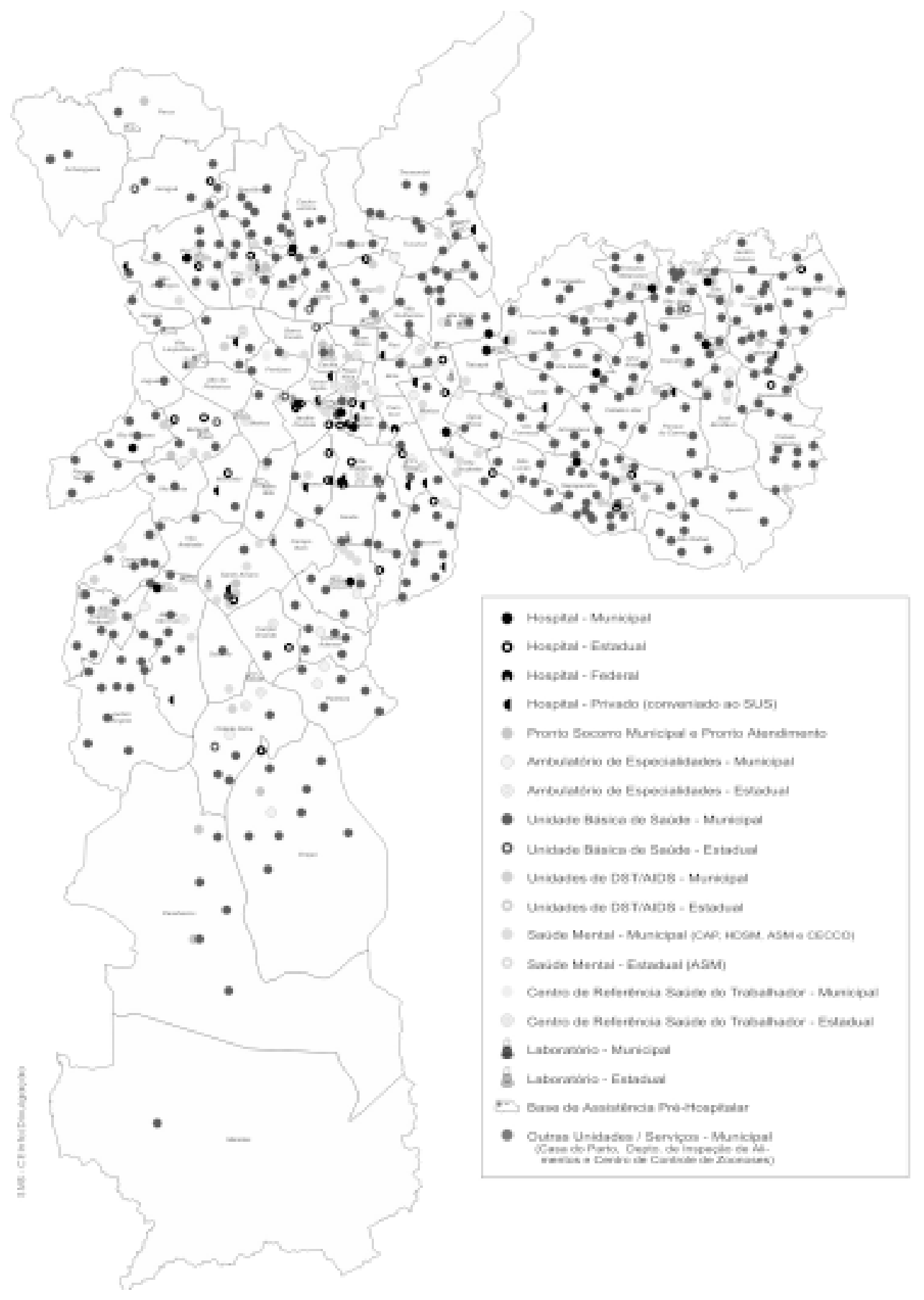

Fonte: CEInfo - SM S, 2002. 
M apa 2 - D istribuição de U nidades de Saúde por área de abrangência dos H ospitais-líder (Santa Casa de M isericórdia, H ospital Santa M arcelina,

H ospital São Paulo - U nifesp, H ospital das Clínicas - U SP). 2002.

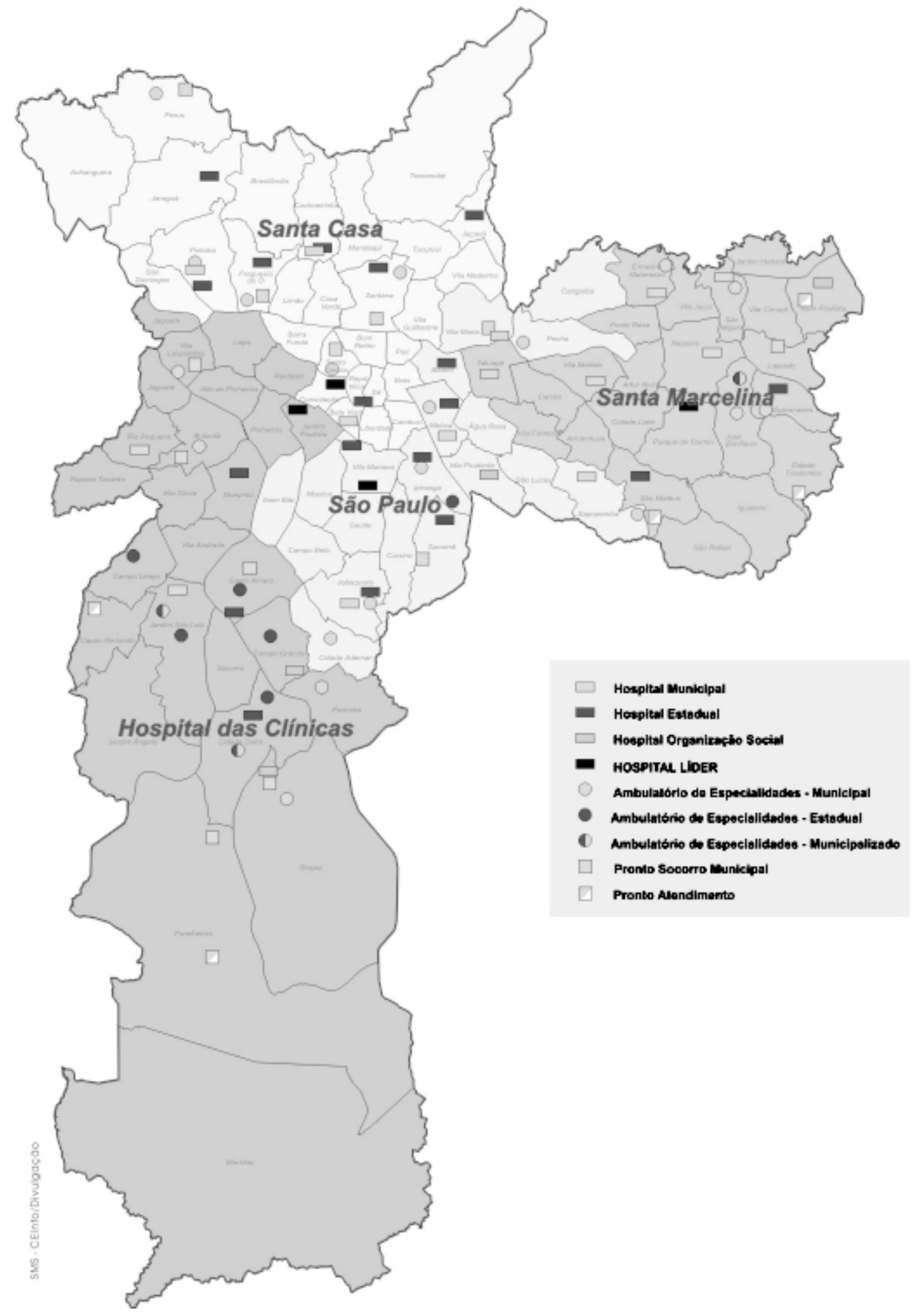

Fonte: CEInfo - SM S, 2002. 
M apa 3 - M unicípio de São Paulo dividido em 39 D istritos de Saúde segundo Distritos Administrativos, 2002.

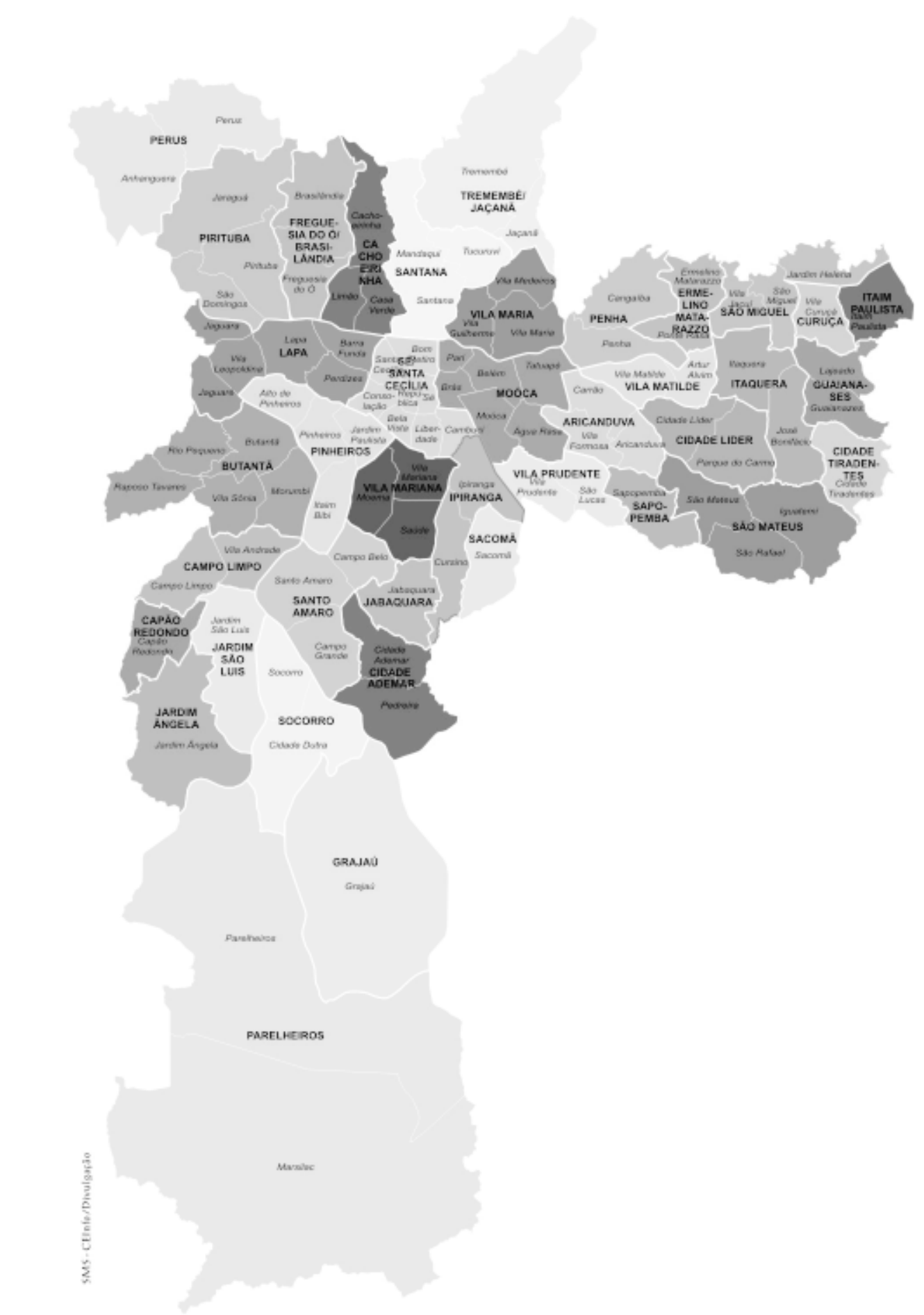

Fonte: CEInfo - SM S, 2002. 
M apa 4 - M unicípio de São Paulo. Área de abrangência das cinco autarquias hospitalares municipais por subprefeituras, 2001.

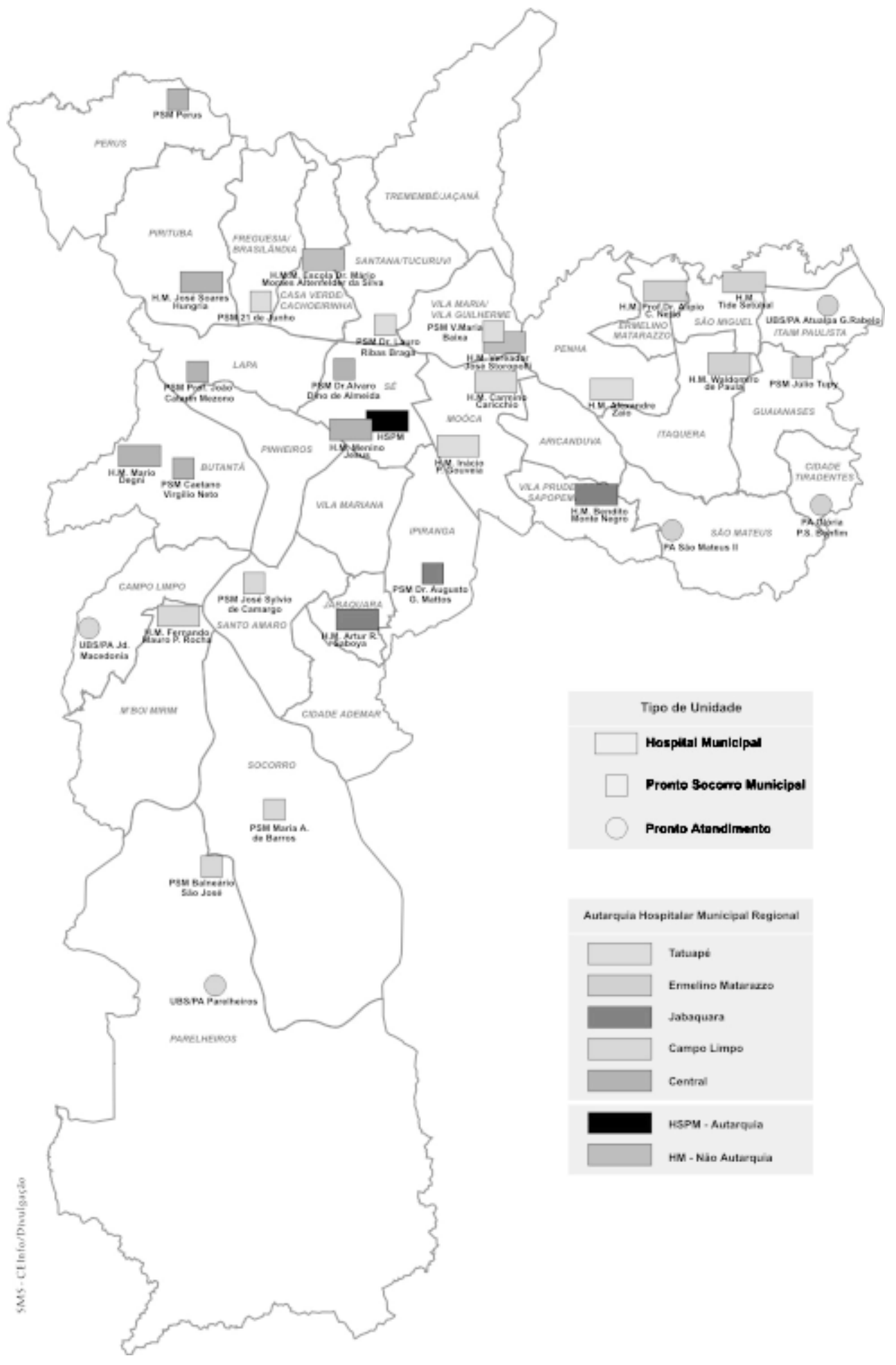

Fonte: CEInfo - SM S, 2002. 


\section{Alguns pontos de destaque}

Ao nosso ver, como já mencionado aqui e em outros tantos lugares, as principais características do SU S são a universalidade, a descentralização, a democratização e a integralidade. E o seu principal problema é o financiamento insuficiente.

A democratização em São Paulo partiu dos sobreviventes/ resistentes do Conselho M unicipal de Saúde (é o primeiro do Brasil, formado em 1989) que haviam sido esmagados nos anos anteriores e chegamos já há quase outros trezentos conselhos distritais, locais, de autarquias etc. De trinta conselheiros fomos para mais de quatro mil. Seguimos com dezenas de cursos de formação de conselheiros sobre o SU S. E a participação social ganhou vivacidade desde a intervenção local no acolhimento na porta da U nidade Básica de Saúde, até no acompanhamento do orçamento municipal de saúde. Q uestões chaves da nossa agenda municipal foram decididas no voto. Por exemplo, a adoção em abril de 2001 da estratégia saúde da família foi decidida no Conselho M unicipal de Saúde por apenas um voto a mais que os votos necessários. O utro exemplo, o envio para Câmara M unicipal no final de 2001 do projeto de lei criando as cinco autarquias municipais hospitalares foi decidido no voto pelos dois mil delegados da Conferência M unicipal de Saúde (70\% a favor, 30\% contrários).

A descentralização caminhou por dois caminhos que tendem a convergir: criação, em janeiro de 2001, de 41 distritos de saúde, cada um responsável por cerca de 250 mil habitantes e entendimentos com os governos estadual e federal para a municipal ização da rede sob responsabilidade do governo estadual sediada na capital, como veremos mais aprofundadamente neste artigo.

A universalização passa pela vigorosa recuperação da rede sucateada por oito anos sem qualquer reforma, equipamento novo, expansão e recomposição do quadro de pessoal. Éramos 42 mil no final do governo Erundina. Começamos o governo M arta com trinta mil trabal hadores e já somos 44 mil em janeiro de 2003, apesar da resistência tenaz da nossa Secretaria M unicipal de Finanças. São Paulo é chave para o SU S neste aspecto, pois é para lá que migram os casos mais crônicos e complexos de todo o país, além de um contigente expressivo de migração latino-americana, que tempera com o espanhol os sotaques presentes nas nossas filas.

A universalidade está intimamente ligada à integralidade. Esta é uma equação não resolvida pelo SU S. U m problema empolgante para sua saída da infância para a adolescência. I sso nos obriga, em São Paulo, por exemplo, a recuperar e expandir o maior programa de controle de Aids do país, pensar na articulação inédita de gigantescos complexos hospitalares como a maior Santa C asa do Brasil, o H ospital Santa M arcelina, maior entidade filantrópica do Brasil, e hospitais universitários do porte do H ospital das C línicas da U SP e H ospital São Paulo da U nifesp etc. N este ponto, nossa opção para o modelo de atenção foi apostar al to no potencial revolucionário do Programa Saúde da Família. 
A queda da mortalidade infantil em ritmo diferenciado nos $D$ istritos com maior cobertura do PSF, a adesão dos usuários, sua capacidade de humanizar as relações profissional saúde/ cidadão usuário, sua força racionalizadora na articulação da rede hospitalar e especializada com a rede básica, a adesão das grandes universidades por meio dos D istritos de Saúde E scola ${ }^{3}$ criados mostram o acerto de nossa escolha política e orçamentária.

$\mathrm{N}$ a questão financiamento, recebemos um orçamento municipal de $12,95 \%$ para saúde em 2001, chegamos a 14,79\% em 2002 e aprovamos 15,02\% para 0 orçamento 2003. O cumprimento por parte do E stado daEC 29/ 2000 vem mais devagar e o governo federal está nos repassando regularmente o Pacto da Atenção Básica - PAB, além dos incentivos específicos da atenção básica. Porém, na produção hospitalar e especializada dos oito milhões de reais mensais a que temos direito, só está nos repassando 3,5 milhões. E isto após longa negociação com o Governo Fernando $\mathrm{H}$ enrique Cardoso. Em fevereiro de 2003, estivemos no M inistério da Saúde do Governo Luís I nácio Lula da Silva, que nos negou, por enquanto espero, qualquer tostão a mais neste item de produção de serviços.

M as não tenhamos dúvidas. A Emenda Constitucional 29/ 2000 foi uma grande vitória. A saúde é a única área de política pública social que, a partir desta emenda, está ampliando sua fatia orçamentária, porém é preciso mais. Em São Paulo ou no Nordeste, no Sul ou no Norte, nossa média de gastos públicos (federal, estadual, municipal) não ultrapassa setenta centavos de real por pessoa por dia4. O SU S faz milagre com estes poucos pães e peixes.

O utro elemento importante em São Paulo foi a incorporação ativa da rede formada por meio das grandes universidades, da rede filantrópica, de grandes hospitais privados e de entidad es de assistência social. $\mathrm{N}$ a instalação e administração do PSF, nos DS-escola, e outras atividades, tem sido decisiva a participação das entidades parceiras.

U m capítulo que atravessa todos os demais é o referente aos recursos humanos. Recuperação salarial, acolhimento, formação de pessoal, concursos públicos (para o desespero da Secretaria M unicipal de Finanças!). O s concurso s foram real izados e mais de quinze mil trabalhadores foram admitidos como estatutários e celetistas em dois anos de trabalho. A saúde foi pioneira em estabelecer na Prefeitura uma mesa permanente de negociações e, apesar de todas as distorções e injustiças que só parcialmente foram corrigidas, o diálogo permanente nos permitiu atravessar toda essa tormenta sem qualquer movimento grevista.

\section{E lementos direcionadores da gestão do SU S no município de São Paulo}

U m pressuposto fundamental adotado desde o início do governo é de que a getão constitui o foco privilegiado para uma intervenção eficaz na implantação do SU S no município de São Paulo, pois é por meio dela que desenvolvemos as diferentes modalidades de assistência à saúde. Para fins deste texto, gestão do 
sistema refere-se à articulação público/ privado que estrutura e regula um sistema, significando, em nosso caso, a atividade e a responsabilidade de dirigir um Sistema de Saúde mediante o exercício de funções de coordenação, articulação, negociação, planejamento, controle, avaliação e auditoria; enquanto modalidades de assistência significam as maneiras de se organizar os serviços de assistência à saúde (que configuram os chamados modelos assistenciais) e cujo núcleo principal é a organização do processo de trabalho. A qui também tratamos a gerência como a responsabilidade de dirigir um ponto de prestação de serviço de qualquer complexidade e densidade tecnológica no Sistema de Saúde (SM S 2001a; 2001b).

Assim, a implantação do SU S em São Paulo exigiu - e ainda exige como processo em curso - profundas mudanças na modalidade de gestão vigente bem como na maneira de se organizar os serviços de saúde. Em linhas gerais, tais mudanças devem rejeitar o modelo burocrático de gestão, caracterizado dentre outros aspectos pelo grande número de estruturas intermediárias decisórias, 0 controle político exercido por meio da estrutura administrativa hierarquizada e a diluição da responsabilidade político-administrativa (SM S 2001a; 2001b; 2001d). Ao contrário, devem ser adotadas modalidades de gestão mais flexíveis e ágeis com autonomia administrativa e gerencial nos serviços de saúde, com incremento de responsabilidade dos gerentes dos serviços e desenvolvimento de instrumentos de controle e avaliação de desempenho (qualidade e quantidade da produção), na prestação de assistência e cumprimento dos compromissos ajustados em planos e acordos de gestão estabelecidos entre os diferentes níveis de gestão do SU S municipal, a serem articulados em âmbito distrital do Sistema M unicipal de Saúde. A organização dos serviços de saúde deve evoluir de forma integrada entre estruturas e funções gerenciais e gestoras em benefício dos usuários dos serviços (demanda), invertendo a lógica clássica de sua estruturação, ou seja, a organização de serviços e processos de trabalho voltados para os interesses do próprio serviço ( oferta) e os vários segmentos profissionais que o compõem. I sto significa conceber os serviços de saúde não como um fim em si, como classicamente vem ocorrendo, mas sim como meio de se atender as necessidades sociais, expressas mais imediatamente pelas demandas de assistência à saúde do cidadão.

C onsoantes às diretrizes anteriores foram definidos os seguintes el ementos de implantação do SU S em São Paulo (SM S, 2001a; 2001b e 2001d):

- a adoção do Programa de Saúde da Família como modalidade estruturante da assistência à saúde, o que implica a sua articulação à rede de U nidades Básicas de Saúde no sentido de tomar-se por referência a lógica do PSF na organização do processo de trabalho nestas unidades;

- planejamento de saúde descentralizado, com ênfase no D istrito de Saúde e foco principal na população, o que implica a consideração dos deslocamentos da população em função do trabalho (este ainda o principal elemento na ordenação da lógica de funcionamento da cidade) visà-viso domicílio caracterizado como local de moradia, face à necessidade de início de um 
processo de adscrição de clientela. As populações descobertas de serviços de assistência à saúde deverão constituir-se em objeto de atenção especial da instância de planejamento no sentido de se buscarem soluções flexíveis, ousadas e criativas capazes de responder às principais demandas da po pulação por serviços de assistência médica;

- compartilhamento do planejamento macroregional com a esfera estadual por meio da criação de instâncias de articulação Estado/ M unicípio ${ }^{5}$, para racionalizar e potencializar o acesso da população à assistência médica secundária e terciária;

- estabelecimento de organismo autônomo onde os quatro grandes hospitais universitários de referência no município (H ospital das Clínicas da Faculdade de M edicina da U niversidade de São Paulo, Santa Casa de M isericórdia de São Paulo, H ospital Santa M arcelina e o H ospital São Paulo da E scola Paulista de M edicina - U niversidade Federal de São Paulo), a SM S e a SE S organizem conjuntamente a assistência à saúde mais complexa na Região M etropolitana da Grande São Paulo;

- a adoção do conceito de Sistema Integrado de Saúde, o que implica a efetivação da integração inter e entre níveis de atenção à saúde;

- efetivação da máxima autonomia administrativa e de organização do processo de trabalho às unidades de serviços de saúde observando a agenda de compromissos acordada no Sistema, medindo-se constantemente o impacto social do trabalho realizado;

- implementação de processo gerencial orientado por sistemas de informação adequadamente informatizados;

- adoção de prioridades/ necessidades em saúde como elemento central do planejamento, realizado de forma ascendente a partir do processo de territorialização distrital, tendo como referência os ciclos de vida. Para tal, devem ser desenvolvidos novos instrumentos de planejamento e adaptados aqueles já existentes. Surgiram assim, por exemplo, os indicadores de mortalidade por ciclo de vida, o painel de monitoramento dos indicadores de condições de vida e saúde, que compõem com outros instrumentos um Plano de Gestão D istrital de Saúde.

\section{Situação de saúde dos D istritos de Saúde do Município de São Paulo ${ }^{6}$}

\section{Índice Saúde}

U ma etapa importante na operação do SU S na cidade de São Paulo é o estabelecimento de formas de avaliação das ações realizadas. Apesar de existir hoje um alto grau de sistematização de normas e regulamentações no SU S envolvendo indicadores de avaliação das ações executadas, pouco se avançou, em termos federal ou estadual, na perspectiva da análise intramunicipal, algo essencial para uma cidade com a dimensão da capital paulista, hoje com mais de dez mi- 
Ihões de habitantes distribuídos nos 39 D istritos de Saúde. 0 uso de indicadores para avaliação de ações descentralizadas e a análise interdistrital pode contribuir na promoção da equidade por meio do diagnóstico dos principais problemas de saúde, sua expressão nos diferentes espaços da cidade e os resultados al cançados com a política de saúde em nível descentralizado. Entende-se que o acesso, a atuação e a qualidade dos serviços de saúde são determinantes fundamentais das condições de saúde da população. A adoção de um índice de saúde distrital na cidade de São Paulo vai ao encontro da missão da Secretaria M unicipal de Saúde de se comprometer com a transparência das suas ações, democratizando e divulgando para toda a sociedade os resultados alcançados pela atuação do SU S municipal.

A iniciativa da adoção do Índice-Saúde como instrumento de avaliação da SM S é mais um elemento do projeto de construção do "Painel de M onitoramento das Condições de Vida e Saúde da População e da Situação dos Serviços de Saúde" que envolve a definição de indicadores de acompanhamento da gestão para as diversas atividades, nos seus diferentes níveis e abarcando diferentes aspectos dos projetos executados na SM S. Projeto de tal envergadura mereceria espaço próprio de detalhamento para conhecimento e estudo do método, o que, no entanto, não será objeto deste artigo, que incluiu este item a fim de divulgar os primeiros resultados e ilustrar a situação de saúde que a organização de um sistema de oferta de assistência na cidade de São Paulo deve enfrentar.

O s objetivos centrais do Í ndice Saúde são:

1. permitir o acompanhamento geral da atuação da Secretaria M unicipal da Saúde através de seus D istritos de Saúde visando a uma melhoria global da qualidade e à adequação das ações de saúde nos âmbitos da promoção da saúde, da prevenção de doenças e da assistência;

2. avaliar os compromissos sociais adotados pela SM S na Cidade de São Paulo de forma sintética e continuada;

3. estimular e avaliar globalmente as políticas de promoção da eqüidade.

O Índice Saúde foi composto de modo a: a) focar o acompanhamento de resultados através de um índice sintético; b) utilizar indicadores que informem so bre as necessidades de to da a população e não se restrinjam à oferta e à demanda de serviços; c) abarcar um grande número de problemas de saúde que tenham relevância para avaliar a qualidade e a adequação das atividades dos serviços de saúde nos âmbitos da promoção, prevenção e assistência à saúde; d) englobar um amplo espectro de temas sob responsabilidade dos serviços públicos de saúde, desde ações da atenção básica até aquelas voltadas para as urgências e emergências; e) articular com indicadores de avaliação utilizados pelo SU S que informam sobre o andamento da atenção básica constantes no PAB (Pacto da A tenção Básica), no elenco de Indicadores de Avaliação da G estão (IAG) e na Agenda M unicipal.

O Índice Saúde é uma síntese dos seus componentes. Foram escolhidos os seguintes indicadores para a composição do Índice sintético: 
1. C oeficiente de M ortalidade I nfantil

2. Coeficiente de Incidência de Tuberculose

3. M ortalidade Precoce por D oenças C rônicas não Transmissíveis

4. Coeficiente de M ortalidade por Causas Externas

O M apa 5 e a Tabela 1 que seguem ilustram as diferenças existentes em cada $D$ istrito de Saúde e mostram a necessidade de abordagem da demanda por ações de saúde segundo o menor território possível em uma cidade de contrastes tão difusos e complexos quanto São Paulo.

M apa 5 - Índice Saúde - posição final dos 41 D istritos de Saúde do M unicípio de São Paulo. 2001.

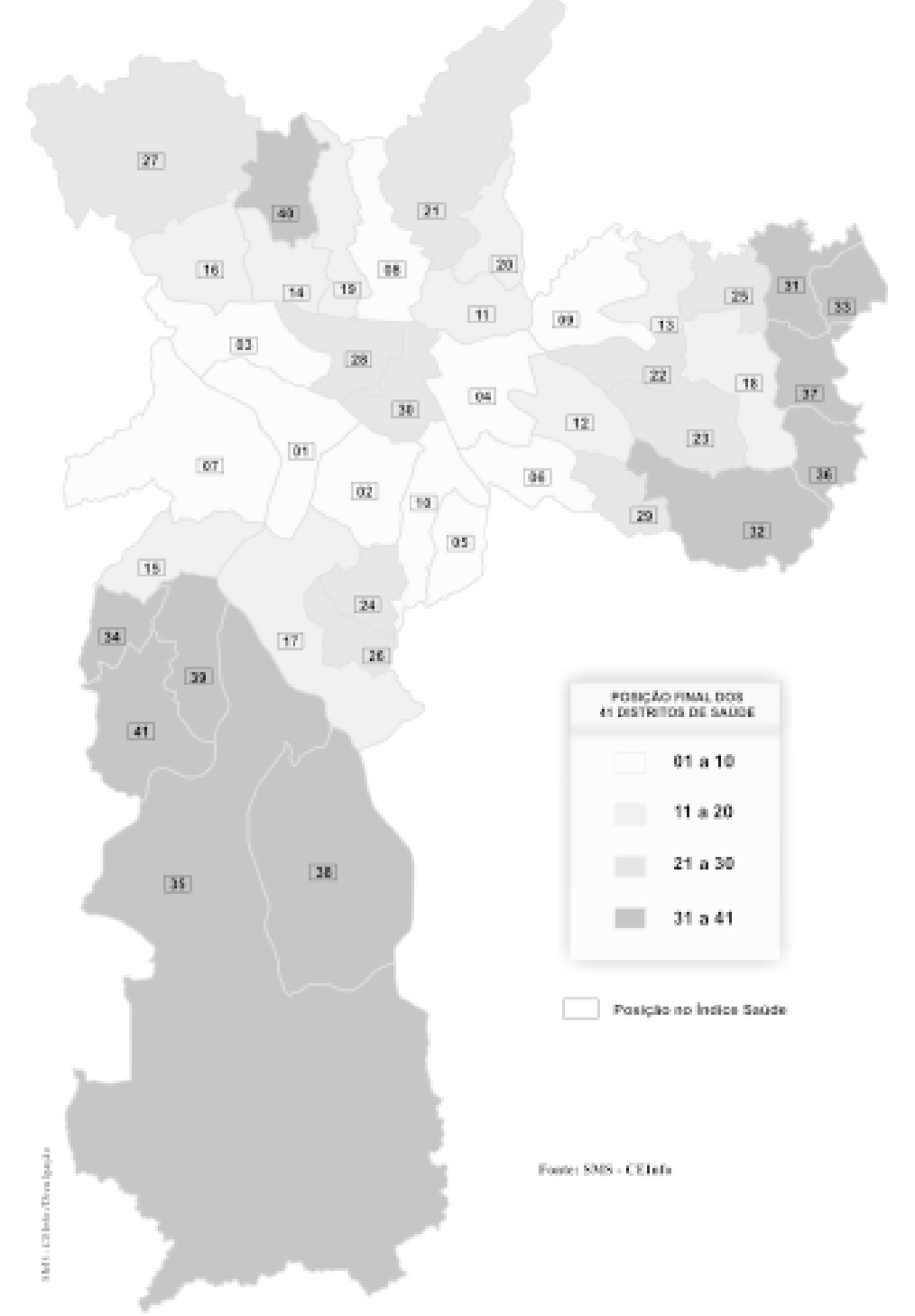

Fonte: Índice Saúde - situação dos D istritos de Saúde do M unicípio de São Paulo. J unho de 2002, (SM Sf, 2002). 
Tabela 1. Índice Saúde - Síntese por Distrito de Saúde do M unicípio de São Paulo, 2002.

\begin{tabular}{|c|c|c|c|c|c|c|}
\hline \multirow[t]{2}{*}{ Distrito de Saúde } & \multicolumn{4}{|c|}{ VALOR NO ÍNDICE SAÚDE } & \multirow{2}{*}{$\begin{array}{l}\text { ÍNDICE } \\
\text { SAÚDE }\end{array}$} & \multirow[t]{2}{*}{ Classificaçãc } \\
\hline & CMI & CIT & MPDC & MCE & & \\
\hline Pinheiros & 1,000 & 0,969 & 1,000 & 0,963 & 0,983 & 1 \\
\hline Vila Mariana & 0,827 & 0,912 & 0,882 & 1,000 & 0,905 & 2 \\
\hline Lapa & 0,679 & 0,874 & 0,865 & 0,876 & 0,823 & 3 \\
\hline Moóca & 0,711 & 0,825 & 0,832 & 0,782 & 0,787 & 4 \\
\hline Sacomã & 0,884 & 1,000 & 0,707 & 0,532 & 0,781 & 5 \\
\hline Vila Prudente & 0,745 & 0,871 & 0,681 & 0,777 & 0,769 & 6 \\
\hline Butantã & 0,809 & 0,689 & 0,665 & 0,856 & 0,755 & 7 \\
\hline Santana & 0,821 & 0,487 & 0,776 & 0,924 & 0,752 & 8 \\
\hline Penha & 0,831 & 0,781 & 0,710 & 0,584 & 0,726 & 9 \\
\hline Ipiranga & 0,735 & 0,792 & 0,729 & 0,568 & 0,706 & 10 \\
\hline Vila Maria & 0,962 & 0,511 & 0,757 & 0,544 & 0,694 & 11 \\
\hline Vila Formosa & 0,426 & 0,850 & 0,701 & 0,713 & 0,672 & 12 \\
\hline Ermelino Matarazzo & 0,451 & 0,698 & 0,719 & 0,591 & 0,615 & 13 \\
\hline Freguesia do Ó & 0,654 & 0,512 & 0,604 & 0,630 & 0,600 & 14 \\
\hline Campo Limpo & 0,528 & 0,858 & 0,292 & 0,723 & 0,600 & 15 \\
\hline Pirituba & 0,426 & 0,778 & 0,566 & 0,628 & 0,599 & 16 \\
\hline Santo Amaro & 0,433 & 0,687 & 0,660 & 0,589 & 0,592 & 17 \\
\hline Itaquera & 0,795 & 0,615 & 0,411 & 0,483 & 0,576 & 18 \\
\hline Cachoeirinha & 0,634 & 0,559 & 0,579 & 0,408 & 0,545 & 19 \\
\hline Jaçanã & 0,382 & 0,706 & 0,645 & 0,444 & 0,544 & 20 \\
\hline Tremembé & 0,264 & 0,597 & 0,654 & 0,654 & 0,542 & 21 \\
\hline Vila Matilde & 0,242 & 0,633 & 0,569 & 0,707 & 0,538 & 22 \\
\hline Cidade Lider & 0,364 & 0,791 & 0,398 & 0,582 & 0,534 & 23 \\
\hline Jabaquara & 0,455 & 0,503 & 0,713 & 0,440 & 0,528 & 24 \\
\hline São Miguel & 0,551 & 0,476 & 0,520 & 0,489 & 0,509 & 25 \\
\hline Cidade Ademar & 0,771 & 0,806 & 0,339 & 0,094 & 0,502 & 26 \\
\hline Perus & 0,171 & 0,829 & 0,390 & 0,520 & 0,477 & 27 \\
\hline Santa Cecilia & 0,356 & 0,086 & 0,787 & 0,668 & 0,474 & 28 \\
\hline Sapopemba & 0,301 & 0,826 & 0,318 & 0,440 & 0,471 & 29 \\
\hline Sé & 0,427 & 0,000 & 0,801 & 0,609 & 0,459 & 30 \\
\hline Curuçá & 0,272 & 0,760 & 0,342 & 0,446 & 0,455 & 31 \\
\hline São Mateus & 0,264 & 0,816 & 0,260 & 0,392 & 0,433 & 32 \\
\hline Itaim Paulista & 0,520 & 0,420 & 0,301 & 0,438 & 0,420 & 33 \\
\hline Capão Redondo & 0,181 & 0,635 & 0,412 & 0,330 & 0,389 & 34 \\
\hline Parelheiros & 0,000 & 0,823 & 0,493 & 0,238 & 0,389 & 35 \\
\hline Cidade Tiradentes & 0,108 & 0,711 & 0,000 & 0,486 & 0,326 & 36 \\
\hline Guaianases & 0,091 & 0,564 & 0,200 & 0,396 & 0,313 & 37 \\
\hline Grajaú & 0,176 & 0,950 & 0,044 & 0,077 & 0,312 & 38 \\
\hline Jardim São Luiz & 0,047 & 0,619 & 0,271 & 0,247 & 0,296 & 39 \\
\hline Brasilândia & 0,473 & 0,147 & 0,324 & 0,192 & 0,284 & 40 \\
\hline Jardim Ângela & 0,276 & 0,754 & 0,092 & 0,000 & 0,281 & 41 \\
\hline
\end{tabular}

Fonte: Índice Saúde - situação dos D istritos de Saúde do M unicípio de São Paulo. Junho de 2002, (SM Sf, 2002). 


\section{Comentários finais}

As grandes reformas estruturais iniciadas em janeiro de 2001 em São Paulo têm períodos variados de maturação em meio à implantação do Sistema Ú nico de Saúde no Brasil, um desafio para os próximos anos que requer pensar novas formas de expansão sustentada, de modo a cumprir com o mandato constitucional e se consolidar como política pública nacional que garanta o direito à saúde de todos os brasileiros. N ossa esperança em vencer as dificuldades atuais, aqui em São Paulo e no plano nacional, está calcada em experiências internacionais semeIhantes e em experiências de muitos municípios brasileiros que nesses catorze anos dessa reforma de estado chamada SU S, têm provado que é possível construir na nossa época de globalização uma política que seja universalista e promotora da coesão nacional.

A descentralização e a regionalização da assistência devem continuar a ocupar a pauta dos administradores, políticos e acadêmicos que vêm se dedicando à essa histórica tarefa de âmbito público e social. O s mecanismos de pactuação e os acordos de gestão devem ser levados ao seu limite tanto no âmbito local como regional, especialmente o metropolitano. Sem uma concertação que reúna os governos municipais e as instâncias do governo estadual para debater e buscar soluções articuladas no âmbito da região metropolitana da grande São Paulo, será bastante difícil obter ganhos no campo da racionalidade no uso dos recursos e dos resultados em termos de condições estáveis de saúde para uma população de mais de dezesseis milhões de habitantes.

A questão do financiamento não é menos importante, e o encontro de uma equação que alie investimentos contínuos para ampliação do acesso a ações e serviços de saúde à sustentação pública do sistema, torna-se crucial na segunda década do processo histórico definido a partir de outubro de 1988.

A opção pelo fortalecimento decisivo da atenção básica - via PSF - com adscrição da população potencialmente usuária em cada unidade do Sistema como elemento reestruturante e racionalizador da assistência, a G estão Plena do Sistema do Sistema M unicipal nas grandes cidades e regiões metropolitanas, o desenvolvimento de mecanismos eficazes de vigilância à saúde, a incorporação definitiva de políticas públicas intersetoriais que se articulam em uma agenda de eventos promotores de melhores condições de vida e saúde, tanto nas pequenas cidades como nos complexos territórios conurbados em forma de grandes metrópoles em to das as regiões do país, são pontos de uma agenda inadiável para aqueles se ocupam e se preocupam com o sucesso da política pública de maior expressão social que o Brasil já experimentou. O SU S é tarefa de um Estado redistribuidor de direitos e bem-estar, e desta forma exige de seus interlocutores junto à população esforço a altura, quer sejam técnicos e trabalhadores do sistema, políticos de mandato executivo ou legislativo, ou lideranças dos diversos segmentos de nossa sociedade. 
Finalmente, a pauta mais difícil, por ser a mais nova, até mesmo no nosso campo socialista: a defesa firme da tese de que o SU S é nacional, ou seja, não tem dono, não deve ser objeto desta nociva obsessão imposta aos governantes pelos marqueteiros que só vale a pena investir naquilo que vira "marca" própria daquele governante. Vejam que nós resistimos e no nosso mais importante investimento, o PSF , usamoso "nome genérico" e não aceitamos rebatizá-lo com fins partidários.

A presença nos nossos mais importantes cargos (diretores de distritos e diretores de autarquias/ hospitais) de servidores federais, estaduais e municipais dos mais variados partidos ou de partido nenhum, desde que com compromisso com o SU S, foi uma batalha ganha a cada dia e que contribuiu para nossa saída em fevereiro de 2003. Porém, o tempo que a bandeira ficou desfraldada foi suficiente para espalhar por muitos ventos que este é um dos pontos mais importantes para a perenidade e para o futuro do SU S no Brasil.

Em uma cidade como São Paulo, essas questões adquirem contornos dramáticos, pois uma cidade-país como a capital do mais poderoso Estado da federação tem a obrigação de liderar esse avanço iminente e crucial. C omo equacionar as soluções necessárias é uma questão que ainda procura uma resposta compatível com o desafio apontado. Porém, podemos afirmar que elas não virão a partir da simples reprodução de formatos e modelos burocráticos esgotados, calcados em relações corporativistas e partidárias, que almejam objetivos exclusivos e de curto prazo, que pouco ou nada ajudam a firmar as bases de uma política do porte que se exige para garantir acesso universal e integral à saúde a todos os brasileiros, um direito inscrito com clareza na Constituição do país e forjado em lutas populares de décadas da história recente e remota de nosso país.

\section{N otas}

10 Gerus, em São Paulo, é aplicado a todos os gerentes de unidade básica de saúde por intermédio de um convênio realizado entre a SM S, a O rganização Panamericana da Saúde - O pas, o M inistério da Saúde e a Faculdade de Saúde Pública da U niversidade de São Paulo. 0 curso tem 360 horas de estudos e trabal hos realizados no próprio espaço de trabalho e conclui com uma análise detalhada das condições de saúde e planejamento de oferta de serviços integrados no território distrital.

2 N a implantação do PSF em São Paulo, fizeram parcerias com a SM S: 1) Associação Comunitária M onte Azul, 2) Associação Congregação Santa Catarina, 3) Instituto Adventista de Ensino - IAE , 4) Centro de Estudos e Pesquisas "D r. João Amorim" C ejam, 5) Fundação Faculdade de M edicina da universidade de São Paulo, 6) Casa de Saúde Santa M arcelina, 7) U niversidade Federal de São Paulo - U nifesp, 8) Associação Saúde da Família, 9) I rmandade da Santa Casa de M isericórdia de São Paulo, 10) U niversidade de Santo A maro - U nisa, 11) Sociedade Beneficente I sraelita Brasileira H ospital Albert Einstein e 12) Fundação Zerbini.

3 Foram criados, até dezembro de 2002, quatro D istritos de Saúde E scola: Butantã, em parceria com a U niversidade de São Paulo; Sacomã e Vila M aria com a U niversidade Federal de São Paulo; e Parelheiros/ Grajaú com a U niversidade de Santo Amaro - 
U nisa. Estava em discussão, até fevereiro de 2003, a criação de mais um Distrito escola na zona leste de São Paulo em parceria com a I rmandade de Santa M arcelina.

40 orçamento nacional para a saúde totalizou cerca de quarenta bilhões de reais em 2002 que, divididos por 170 milhões de habitantes e por 365 dias do ano, perfaz a cifra de $\mathrm{R} \$ 0,70$ por habitante/ ano gastos em saúde.

5 Essa ação, depois de exercícios vários, veio culminar, em fevereiro de 2003, com a instalação de uma Comissão Intergestores Regional para a capital, composta pela Coordenação Regional de Saúde I da Secretaria Estadual da Saúde - DIR-I, e por representantes da Secretaria M unicipal de Saúde de São Paulo, como também com a criação de uma comissão técnica assessora da Comissão Intergestores Bipartite do Estado de São Paulo, composta pela DIR-I e Coordenadoria de Planejamento de Saúde da SES-SP, por quatro municípios representantes da R egião M etropolitana da Capital apontados pelo Cosems-SP e por três representantes da SM S-SP.

6 Este trecho do artigo é quase todo composto a partir de uma transcrição editada do documento intitulado "Í ndice Saúde - situação dos D istritos de Saúde do M unicípio de São Paulo" de, junho de 2002, apresentado pela CEInfo - Coordenação de E pidemiologia e Informação da SM S sob coordenação do D r. M arcos D rummond Junior (SM Sf, 2002).

\section{Bibliografia}

COH N, Amélia e ELIAS, Paulo E. (coords.). O público e o privado na saúde: o PA S em São Paulo. São Paulo, Cortez/ Cedec, 1999, 248 p.

GIOVAN ELLA, Lígia. "Estratégia e poder no planejamento em saúde". Em FLEU RY, Sônia (org.). Saúde: coletiva? Questionando a onipotência do social. Rio de Janeiro, Relume-D umará, 1992, pp. 45-66.

SM S - Secretaria M unicipal de Saúde de São Paulo. Plano municipal de saúde. M imeo., 1989, 38p.

SM Sa - Secretaria M unicipal de Saúde de São Paulo. D ocumento do I I Encontro de G etores deSM S "D iretrizesePri oridadespara oSi stema M unici pal deSaú deem São Paulo". São Paulo, 3 e 4 ago. 2001, mimeo.

SM Sb - Secretaria M unicipal de Saúde de São Paulo. Comunicado n. 001 Diretrizes Gerais para SM S. D iário O ficial do M unicípio de São Paulo. São Paulo, 25 jan. 2001.

SM Sc - Secretaria M unicipal de Saúde de São Paulo. Comunicado n.o 03 [Estrutura e organização da Secretaria M unicipal de Saúde de São Paulo]. D iário O ficial do M unicípio de São Paulo, 19 jun. 2001.

SM Sd - Secretaria M unicipal de Saúde de São Paulo. Comunicado n. 12 Orientações para o D esenvolvimento do SU S no M unicípio de São Paulo. D iário O ficial do M unicípio de São Paulo. 13 set. 2001.

SM Se - Secretaria M unicipal de Saúde de São Paulo. Comunicado n.o 87 - A dequação do Si stema Municipal de Saúde às Subprefeituras. Diário O ficial do M unicípio de São Paulo, 2002. 
SM Sf - Secretaria M unicipal de Saúde de São Paulo Í ndiceSaúde- situação dosD istritos de Saúde do M unicípio de São Paulo.Coordenador: M arcos D rummond J unior. São Paulo, 2002, 14p.

PM SP - Prefeitura do M unicípio de São Paulo. Le Municipal n.o 13.399. [institui as subprefeituras no município de São Paulo] Diário O ficial do M unicípio de São Paulo. 1ㅇ ago. 2002.

R ESU mo - o ARTIGO apresenta uma análise a partir da vivência dos autores do processo de implantação do Sistema Ú nico de Saúde - SU S - na cidade de São Paulo, Brasil. A borda questões técnicas e políticas acerca da gestão e gerência pública do sistema municipal de saúde em uma cidade de gran de proporção geográfica e populacional, desigual em sua organização territorial e em regime de transição para um modelo de assistência em saúde descentralizado. $\mathrm{N}$ arra e ilustra o processo de distritalização do sistema de saúde e apresenta a situação de saúde no município a partir de um índice sintético de saúde em distritos. Ao final, propõe uma agenda de desenvolvimento do SU S apontando questões essenciais a serem debatidas e equacionados com o fim de tornar o modelo de assistência e as políticas de saúde mais socialmente eficazes e politicamente perenes.

A BSTRACT - THE ARTICLE brings an analysis since the authors lived experiences about the setting of the Sistema Ú nico de Saúde - SU S - the Brazilian national health policy - in the city of São Paulo, Brazil. It takes into consideration both technical and politics issues over the public management of local health system in a city of large geographic and populational proportions, poorly fair in territorial equity. The article describes the meaning of decentralization process as the key to achieve the aims of local health system as well as shows the first results from a local health index. At the end, the authors set an agenda for the SU S development pointing essential debate in order to achieve better results in the health and social status of the Brazilian population and the needs to make the health policies long standing.

Eduardo J orge M artins A Ives Sobrinho é médico sanitarista, ex-deputado federal - PT São Paulo e secretário municipal de Saúde da cidade de São Paulo 2001-2002. Co-autor e autor da legislação constitucional sobre saúde e da Emenda Constitucional no. . 29 de 2000.

Paulo Fernando Capucci é cirurgião dentista e educador em Saúde Pública, mestre em Administração Pública pela EAESP-FGV e doutorando em Saúde Pública pela FSP-U SP. Foi coordenador de gestão descentralizada da Secretaria M unicipal de Saúde de São Paulo 2001-2002.

Texto recebido e aceito para publicação em 11 de junho de 2003. 